\title{
The key role of topography in altering North Atlantic atmospheric circulation during the last glacial period
}

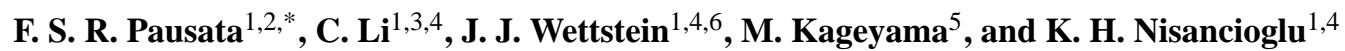 \\ ${ }^{1}$ Bjerknes Centre for Climate Research, Bergen, Norway \\ ${ }^{2}$ Geophysical Institute, University of Bergen, Bergen, Norway \\ ${ }^{3}$ Department of Earth Science, University of Bergen, Bergen, Norway \\ ${ }^{4}$ UNI Bjerknes Centre, Bergen, Norway \\ ${ }^{5}$ Laboratoire des Sciences du Climat et de l'Environnement/IPSL, UMR8212 CEA-CNRS-UVSQ, Gif-sur-Yvette, France \\ ${ }^{6}$ Climate and Global Dyamics, National Center for Atmospheric Research, Boulder, USA \\ *now at: the European Commission, Joint Research Center, Institute for Environment and Sustainability, Ispra (VA), Italy
}

Received: 30 January 2011 - Published in Clim. Past Discuss.: 16 February 2011

Revised: 22 September 2011 - Accepted: 22 September 2011 - Published: 18 October 2011

\begin{abstract}
The Last Glacial Maximum (LGM; $21000 \mathrm{yr}$ before present) was a period of low atmospheric greenhouse gas concentrations, when vast ice sheets covered large parts of North America and Europe. Paleoclimate reconstructions and modeling studies suggest that the atmospheric circulation was substantially altered compared to today, both in terms of its mean state and its variability. Here we present a suite of coupled model simulations designed to investigate both the separate and combined influences of the main LGM boundary condition changes (greenhouse gases, ice sheet topography and ice sheet albedo) on the mean state and variability of the atmospheric circulation as represented by sea level pressure (SLP) and 200-hPa zonal wind in the North Atlantic sector. We find that ice sheet topography accounts for most of the simulated changes during the LGM. Greenhouse gases and ice sheet albedo affect the SLP gradient in the North Atlantic, but the overall placement of high and low pressure centers is controlled by topography. Additional analysis shows that North Atlantic sea surface temperatures and sea ice edge position do not substantially influence the pattern of the climatological-mean SLP field, SLP variability or the position of the North Atlantic jet in the LGM.
\end{abstract}

\section{Introduction}

The Last Glacial Maximum (LGM), approximately $21000 \mathrm{yr}$ before present $(21 \mathrm{ka})$, was the time of maximum land ice volume during the last glacial period (Yokoyama et al., 2000) when global mean surface temperature was 4 to $5 \mathrm{~K}$ lower

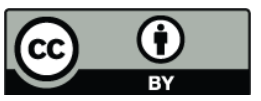

Correspondence to: F. S. R. Pausata (francesco.pausata@jrc.ec.europa.eu) than today (Braconnot et al., 2007; Roche et al., 2007). The main boundary condition changes for the LGM compared to the present climate are in the extent and height of continental ice sheets, and in atmospheric greenhouse gas (GHG) concentrations. Incoming solar radiation was also different, but not greatly so because the geometry of the Earth's orbit around the Sun was close to its present configuration (Table 1). The small insolation differences cannot explain the differences between the LGM and the modern climate, in particular the magnitude of the global mean cooling (Hewitt and Mitchell, 1997; Chiang et al., 2003). On the other hand, the presence of massive ice sheets over North America and Eurasia (Peltier, 2004) and the reduced atmospheric GHG concentrations (Flückiger et al., 1999; Dallenbach et al., 2000; Monnin et al., 2001; Table 1) represent large boundary condition changes for the atmospheric circulation. For example, the atmospheric concentration of carbon dioxide $\left(\mathrm{CO}_{2}\right)$ was almost $100 \mathrm{ppm}$ lower than pre-industrial (PI, $1750 \mathrm{AD}$ ) values, as shown by trace gas analysis from ice cores (Monnin et al., 2001). The volume of water stored in the ice sheets during the LGM is equivalent to $130 \mathrm{~m}$ of relative sea level drop (Yokoyama et al., 2000), which is enough to generate ice sheets over North America and Eurasia up to $5 \mathrm{~km}$ thick (Peltier, 2004).

Previous studies have investigated the simultaneous impact of all these boundary conditions on the LGM climate. For example, using an atmosphere general circulation model (AGCM) forced with proxy-based sea surface temperature (SST) reconstructions, Hansen et al. (1984) showed that most of the global mean LGM cooling is due to the presence of ice sheets and increased sea ice cover. The role of ice sheets in LGM simulations has been further investigated using AGCMs coupled to static slab oceans, with a focus on regional versus global effects as well as on the particular

Published by Copernicus Publications on behalf of the European Geosciences Union. 
Table 1. Boundary conditions for pre-industrial (PI) and Last Glacial Maximum (LGM) simulations. The ranges in square brackets represent the range of possible values for the obliquity and eccentricity of Earth's orbit.

\begin{tabular}{lcccccccc}
\hline & Ice sheet & Vegetation & $\mathrm{CO}_{2}$ & $\mathrm{CH}_{4}$ & $\mathrm{~N}_{2} \mathrm{O}$ & Obliquity & Angular & Eccentricity \\
\hline & & & $(\mathrm{ppmv})$ & $(\mathrm{ppbv})$ & $(\mathrm{ppbv})$ & $\begin{array}{c}\left({ }^{\circ}\right) \\
{[22.0-24.5]}\end{array}$ & $\begin{array}{c}\text { precession } \\
\left({ }^{\circ}\right)\end{array}$ & {$[0.0034-0.058]$} \\
\hline PI & & & & & 23.4 & 102 & 0.017 \\
LGM & Modern & Modern & 280 & 760 & 270 & 22.9 & 114 & 0.019 \\
\hline
\end{tabular}

importance of ice sheet extent (albedo) for surface cooling (Manabe and Broccoli, 1985; Felzer et al., 1996; Hewitt and Mitchell, 1997; Felzer et al., 1998).

Other studies investigated details of the atmospheric circulation response to each LGM boundary condition. An early study using a coarse resolution $\left(8^{\circ} \times 10^{\circ}\right) \mathrm{AGCM}$ found that the various boundary conditions can have opposite influences on the intensity and the location of transient and stationary eddies (Rind, 1987); however, the boundary conditions were applied sequentially rather than tested individually. More recently, Justino et al. (2005) performed a suite of experiments using an Earth system model of intermediate complexity (EMIC) to isolate the individual boundary condition effects. They found that topography is most important for controlling large-scale atmospheric flow, at least in the simplified, coarse resolution atmosphere $\left(5.6^{\circ} \times 5.6^{\circ}\right)$ of the EMIC. Langen and Vinther (2009) used an AGCM to separate the impact of topography and sea surface temperature (SST) on atmospheric circulation and found that the stationary wave pattern is controlled by ice sheet topography. However, none of these studies used fully-coupled atmosphere-ocean GCMs (AOGCMs), and thus they did not include the influence of a dynamically interactive ocean or sea ice cover. Using an AOGCM, Kim et al. (2004) argued that much of the high latitude cooling and sea ice expansion is in fact due to the dynamical ocean response to reduced GHG concentrations alone.

In an intercomparison study of four coupled climate models belonging to the Paleoclimate Modelling Intercomparison Project phase II (PMIP2, http://pmip2.lsce.ipsl.fr), Pausata et al. (2009) analyzed changes in Northern Hemisphere sea level pressure (SLP) and SLP variability in the LGM simulations compared to the preindustrial (1750 AD) simulations. Together with uncoupled sensitivity experiments using one atmosphere GCM, the simulations suggest that ice sheet topography is the most important factor influencing SLP changes, while surface ocean properties (SST and sea ice) play only a minor role. The findings of Pausata et al. (2009) are at variance with those of Byrkjedal et al. (2006), who showed that the LGM position of the Icelandic low in a different atmosphere GCM is affected by the North Atlantic sea ice edge. However, the uncoupled nature of the sensitivity experiments in both these studies and the fact that only one atmosphere GCM was used in each makes it difficult to draw more definitive conclusions.

Most of the studies examining the influence of LGM boundary conditions on the atmospheric circulation are limited by the absence of a fully interactive ocean: either they use a slab ocean model (e.g. Manabe and Broccoli, 1985; Felzer et al., 1996) in which the ocean is highly simplified, or, more commonly, they use an AGCM (e.g. Rind, 1987; Pausata et al., 2009) in which the ocean is treated as a boundary condition rather than as interactive component of the climate system. A fully interactive ocean allows for a dynamical ocean response to the GHG and land ice boundary conditions that can potentially feed back onto the atmospheric circulation and its variability. The current study aims to further investigate the separate and combined influence of LGM ice sheet topography, ice sheet albedo and GHG concentrations in a suite of fully coupled experiments. The goal is to reevaluate the dominant role of ice sheet topography suggested by Pausata et al. (2009) but in a coupled rather than uncoupled framework.

\section{Model and experiments}

The model used in the current study is the Institut PierreSimon Laplace coupled atmosphere-ocean general circulation model (IPSL-CM4-V1, Marti et al., 2010). This model took part in PMIP2, a model intercomparison project with coordinated simulations for the LGM and mid-Holocene climate states (Braconnot et al., 2007). The atmospheric component has a horizontal resolution of $2.5^{\circ} \times 3.75^{\circ}$ on a regular latitude by longitude grid and 19 vertical levels. The ocean component has 31 vertical levels and a horizontal resolution of about $2^{\circ} \times 2^{\circ}$ with a refined grid near the equator and in the Nordic Seas. In this study, the control simulation is the PI climate in which insolation corresponds to a 1950 AD orbital configuration and the GHG concentrations correspond to those that existed around 1750 AD (Table 1). For the LGM simulation, the orbital parameters are set to $21 \mathrm{ka}$ and GHG concentrations are lower than today, corresponding to the LGM values inferred from the Greenland and Antarctic ice cores (Flückiger et al., 1999; Dallenbach et al., 2000; Monnin et al., 2001). In the full LGM, the coastline and topography are set following the ICE-5G reconstruction 
(Peltier, 2004) and sea level is about $130 \mathrm{~m}$ lower than in the PI. To close the LGM fresh water budget, Kageyama et al. (2009) compensated for small and nearly constant imbalances in the atmospheric convection scheme and in snow accumulation on the ice sheets by introducing a surface fresh water flux of $0.08 \mathrm{~Sv}$ to the North Atlantic and Arctic. In all simulations, a modern distribution of vegetation is prescribed (except in the glaciated LGM grid boxes).

In addition to the control (PI) and full LGM simulations, four sensitivity experiments have been performed in which each LGM boundary condition has been applied separately with all other boundary conditions set to PI values: (1) LGM GHG concentrations (LGMghg); (2) LGM land albedo with PI topography (LGMalb); (3) LGM topography with PI albedo (LGMtopo); and (4) LGM topography and albedo (LGMice). The change in coastlines associated with the $130 \mathrm{~m}$ drop in sea level under LGM conditions has been applied for all the experiments with ice sheet forcing (LGMice, LGMtopo, LGMalb), whereas for the LGMghg the sea level is the same as that in the PI simulation. Table 2 summarizes the boundary conditions used in the sensitivity experiments.

We have chosen to apply the changes in boundary conditions in separate experiments with respect to a common reference state: the pre-industrial control. This is different from a suite of experiments applying each forcing sequentially as in Rind (1987) and allows an easier comparison of the impact of each boundary condition change by considering changes relative to a unique reference experiment. The extent to which the full LGM response is different from the sum of the separate boundary condition responses allows for an examination of the non-linearity of the LGM climate response.

The full LGM simulation has an active $(\sim 15 \mathrm{~Sv})$ Atlantic Meridional Overturning Circulation and therefore relatively warm North Atlantic sea surface temperatures. In an attempt to isolate the response of the LGM atmospheric circulation to a surface ocean temperature anomaly, an additional experiment (LGMfw) has been analyzed. The LGMfw experiment is a simulation where an additional $0.1 \mathrm{~Sv}$ fresh water flux is added into the North Atlantic and Arctic Oceans throughout the simulation, causing a collapse of the Atlantic Meridional Overturning Circulation, cooling of the North Atlantic and an expansion of sea ice in the northern North Atlantic. The LGMfw experiment has been integrated for $420 \mathrm{yr}$ starting from year 150 of the full LGM simulation. The LGMfw experiment is described in detail in Kageyama et al. (2009). The experiments labelled LGM and LGMfw in the present study are labelled LGMb and LGMc, respectively, in Kageyama et al. (2009).

Each equilibrium experiment is $500 \mathrm{yr}$ long and the last $100 \mathrm{yr}$ of monthly SLP, 200-hPa zonal wind and surface temperature data from $20^{\circ}-90^{\circ} \mathrm{N}$ are analyzed. The centuryscale trend in the global mean surface air temperature (an indicator of model drift in the simulation) over the last $300 \mathrm{yr}$ of each simulation is less than $0.05 \mathrm{~K} / 100 \mathrm{yr}$ in absolute value,
Table 2. Boundary conditions and coastlines used in the sensitivity experiments.

\begin{tabular}{lcccc}
\hline & LGMghg & LGMalb & LGMtopo & LGMice \\
\hline GHGs & LGM & PI & PI & PI \\
Albedo & PI & LGM & PI & LGM \\
Topography & PI & PI & LGM & LGM \\
Coastline & PI & LGM & LGM & LGM \\
\hline
\end{tabular}

with the exception of the LGMfw experiment, which undergoes continuous freshwater forcing throughout the simulation (Table 3). The century-scale trend in global abyssal ocean temperature (below $2000 \mathrm{~m}$ ) for the last $300 \mathrm{yr}$ of each simulation is shown in Table 3: only the LGMtopo and LGMice experiments show a temperature drift greater than $0.1 \mathrm{~K} / 100 \mathrm{yr}$. These trends $(\sim 0.13 \mathrm{~K} / 100 \mathrm{yr})$ are comparable to the $0.15 \mathrm{~K} / 100 \mathrm{yr}$ trend in abyssal ocean temperature found in a different AOGCM LGM simulation in the slow adjustment period just prior to attaining the full equilibrium (Brandefelt and Otto-Bliesner, 2009). Hence, it is possible that the LGMtopo and LGMice simulations described here have also not reached full equilibrium. However, the surface temperature and atmospheric features we are focusing on are stable over the analyzed period (Table 3), even compared to the surface air temperature trend in the pre-equilibrium period of Brandefelt and Otto-Bliesner (2009) (cf. Table 3 with Fig. 1 in Brandefelt and Otto-Bliesner, 2009).

Anomalies are calculated based on monthly departures from the climatological-mean seasonal cycle to focus on interannual variability. Standard Empirical Orthogonal Function (EOF)/Principal Component (PC) analysis has been applied to SLP anomalies to calculate the leading pattern of SLP variability in the North Atlantic. Simulated differences from the control (PI) for both surface temperature and SLP are almost everywhere significant with $95 \%$ confidence.

\section{Results}

The results presented here describe the effects of the LGM boundary conditions on the mean state and variability of the Northern Hemisphere atmospheric circulation, with a particular focus on the North Atlantic sector. The results are presented in three sections. The first section investigates in a fully coupled framework the suggestion of Pausata et al. (2009) that key features of the large-scale LGM SLP response are determined by topography. In this section, we first examine general features of the Northern Hemisphere and then focus on the Atlantic sector. To allow for a direct comparison with Pausata et al. (2009), the spatial distribution of annual mean SLP and the leading patterns of North Atlantic SLP variability are analyzed. The second section extends the analysis from the surface to the upper troposphere 
Table 3. Global surface air and deep ocean temperature drifts over the last $300 \mathrm{yr}$ of each simulation.

\begin{tabular}{lccccccc}
\hline & PI & LGM & LGMghg & $\begin{array}{c}\text { LGMalb } \\
\text { K 100 yr }^{-1}\end{array}$ & LGMtopo & LGMice & LGMfw \\
\hline Atmosphere & 0.025 & 0.001 & 0.033 & 0.015 & 0.016 & 0.025 & 0.078 \\
Ocean & 0.066 & 0.025 & 0.015 & 0.087 & 0.135 & 0.133 & 0.009 \\
\hline
\end{tabular}

by examining the $200-\mathrm{hPa}$ wind response in the North Atlantic. The third section shows the surface temperature response to various LGM boundary conditions and discusses the influence of surface ocean forcing on the North Atlantic SLP field.

\subsection{Effects of LGM boundary conditions on SLP}

\subsubsection{Northern Hemisphere}

A robust feature of LGM model simulations is a southward shift of the climatological-mean SLP patterns and a general reduction in the interannual variance of SLP in the extratropical Northern Hemisphere (e.g. Pausata et al., 2009; Laîné et al., 2009). Consistent with these previous studies, we note a southward shift of the climatological high (hereafter "subtropical high") and low (hereafter "subpolar low") SLP centers in the North Atlantic (i.e. the Icelandic low and Azores high) and North Pacific (i.e. the Aleutian low and North Pacific high) in our full LGM relative to the PI simulation (Fig. 1 and Table 4). The climatological-mean SLP gradient between the subtropical high and subpolar low weakens in the North Pacific, whereas it strengthens substantially in the North Atlantic in the full LGM simulation compared to the PI simulation (Table 5).

An examination of the sensitivity experiments reveals that topography is the boundary condition that alone creates a SLP distribution most similar to the full LGM simulation (compare LGM and LGMtopo in Fig. 1; also shown in contours for the North Atlantic sector only in Fig. 2). However, the SLP gradient in the Pacific sector is weaker in LGMtopo compared to the full LGM simulation (Table 5). Conversely, the LGMghg and LGMalb simulations exhibit stronger SLP gradients compared to the control simulation, but less change in the location of the subtropical highs and subpolar lows. Thus, the main effect of both greenhouse gases and albedo changes at the LGM is to increase the midlatitude SLP gradient, whereas ice sheet topography shifts the location of the climatological SLP features (Fig. 1, Tables 4 and 5).

\subsubsection{North Atlantic}

In addition to the general reduction in SLP variance, Pausata et al. (2009) reported a reduction in the dominance of the leading pattern of North Atlantic SLP variability in the LGM relative to the PI simulation.
The sensitivity experiments presented here indicate that changes in SLP variability are driven almost entirely by changes in topography (Figs. 1 and 2). Topography is responsible for the change in the pattern of SLP variability, producing a broad decrease in both interannual variability at high latitudes (Fig. 1) and in the total interannual variance explained by the leading pattern (EOF1, Fig. 2), as well as a less defined North Atlantic dipole in EOF1 (Fig. 2). In contrast, both reduced GHG concentrations and increased albedo at the LGM produce a small increase in the SLP standard deviation at mid-to-high latitudes (Fig. 1) and a stronger North Atlantic dipole pattern in EOF1 (Fig. 2). In fact, the leading EOFs in the PI, LGMghg and LGMalb simulations (i.e. the experiments without LGM ice sheet topography, left panels of Fig. 2) resemble the latitudinal shifting of atmospheric mass described by the well-known North Atlantic Oscillation (NAO; Walker and Bliss, 1932). The leading EOFs in the LGM, LGMice and LGMtopo simulations (i.e. the experiments with LGM ice sheet topography) instead represent mostly a change in the intensity and longitudinal extent of the Icelandic low. Similar changes in the NAO/Arctic Oscillation were found in a study by Rivière et. al. (2010) by examining the distribution of Rossby wave breaking events in PI and LGM simulations.

In summary, these coupled model experiments support the suggestion of Pausata et al. (2009), based on uncoupled AGCM experiments, that topography is key in altering the main features of the SLP field. In the full LGM simulation, the pattern of the climatological-mean SLP field, the pattern of SLP variability, and the leading EOF of SLP variability (Fig. 2, Tables 4 and 5) are set almost entirely by the ice sheet topography alone. The GHG and ice sheet albedo boundary conditions are responsible for changes in the SLP gradient and relatively smaller changes in SLP variability and the leading pattern of SLP variability.

\subsection{Effects of LGM boundary conditions in 200-hPa zonal winds}

In this section, we analyze the $200-\mathrm{hPa}$ zonal wind in the North Atlantic sector in order to better characterize the atmospheric circulation response to LGM boundary conditions through the depth of the troposphere.

The full LGM simulation has a strengthened, sharpened and distinctly northward shifted 200-hPa zonal wind maximum compared to the control PI simulation (Fig. 3). The 
PI

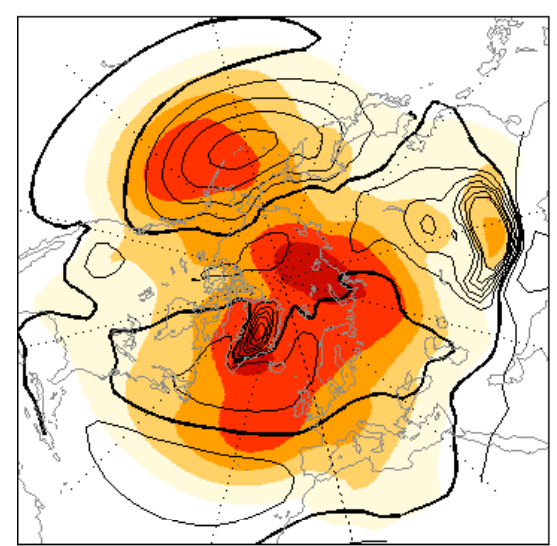

LGMghg-PI

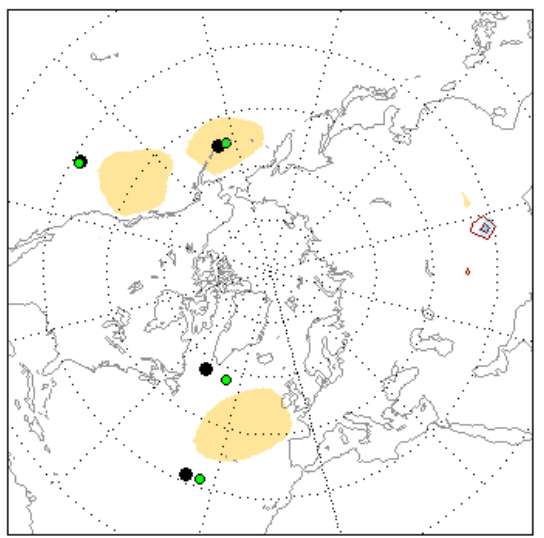

LGMalb-PI

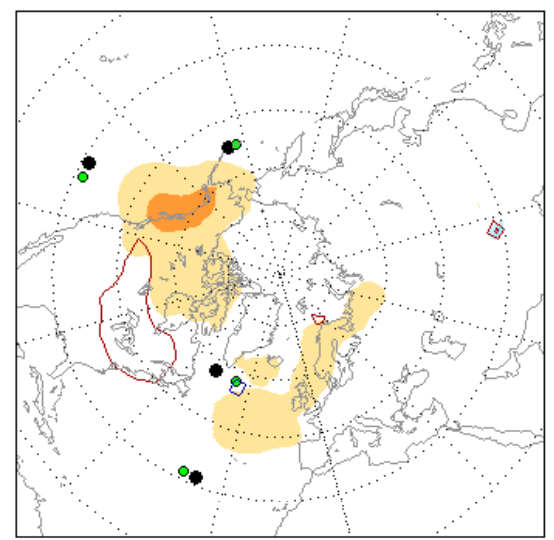

LGM-PI

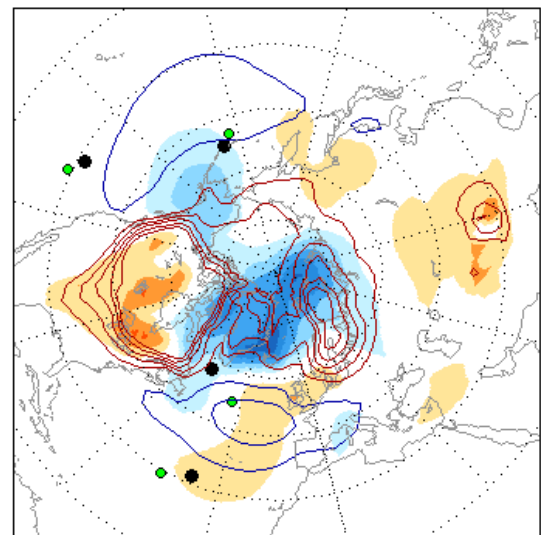

LGMice-PI

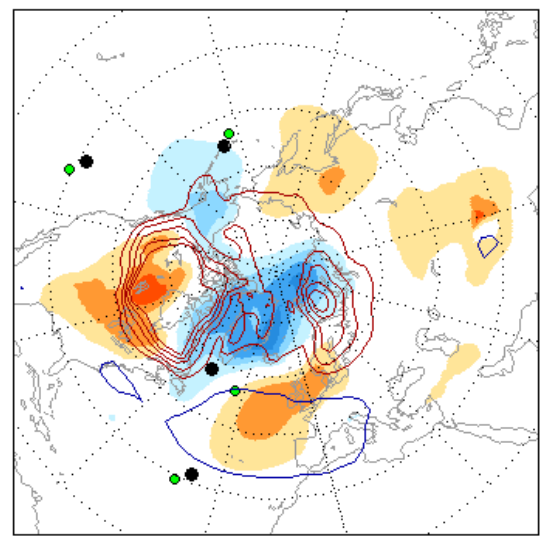

LGMtopo-PI

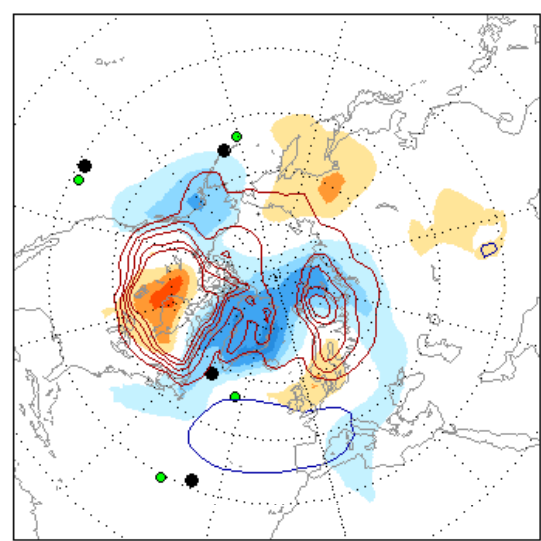

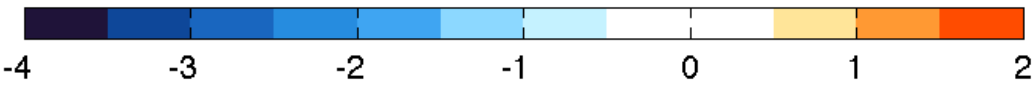

Fig. 1. The top left panel shows the climatological-mean SLP (contours: $4 \mathrm{hPa}$ interval from 1000 to $1040 \mathrm{hPa}$; bold contour denotes $1016 \mathrm{hPa}$ ) and standard deviation of monthly SLP anomalies (colored shading: $1 \mathrm{hPa}$ interval) using data from all months in the control (PI) simulation. The other panels show the difference in the annual mean SLP (contours: $4 \mathrm{hPa}$ interval; blue contours denote negative values, red positive values; the zero line is omitted) and the difference in the monthly SLP standard deviation (colored shading) between the indicated experiment and the control simulation (PI). Dots show the locations of the subpolar lows and subtropical highs in the Pacific and Atlantic sectors for the control simulation (black) and the indicated experiment (green). 
Table 4. Annual-mean position of the subpolar lows and subtropical highs in the Atlantic and Pacific basins for the control (PI) simulation, and the differences between each sensitivity experiment and the PI simulation in degrees $\mathrm{N}$ or E. The locations of SLP lows and highs have been determined by calculating the SLP climatology and then finding the lowest and highest value in each ocean basin (Atlantic: $20-65^{\circ} \mathrm{N}$, 0-60 W; Pacific: $\left.20-60^{\circ} \mathrm{N} ; 120-180^{\circ} \mathrm{W}\right)$.

\begin{tabular}{|c|c|c|c|c|c|c|c|}
\hline & & \multirow{2}{*}{$\begin{array}{c}\text { Positions } \\
\text { PI }\end{array}$} & \multicolumn{5}{|c|}{$\Delta$ Positions } \\
\hline & & & LGM & LGMghg & LGMalb & LGMtopo & LGMice \\
\hline \multirow[t]{2}{*}{ Atlantic } & Low & $57.0^{\circ} \mathrm{N} / 48.5^{\circ} \mathrm{W}$ & $-5.0^{\circ} /+14.5^{\circ}$ & $0^{\circ} /+11.0^{\circ}$ & $0^{\circ} /+11.0^{\circ}$ & $-2.5^{\circ} /+14.5^{\circ}$ & $-2.5^{\circ} /+14.5^{\circ}$ \\
\hline & High & $31.7^{\circ} \mathrm{N} / 37.5^{\circ} \mathrm{W}$ & $-2.5^{\circ} /-7.5^{\circ}$ & $0^{\circ} /+3.75^{\circ}$ & $0^{\circ} /-3.75^{\circ}$ & $-2.5^{\circ} /-7.5^{\circ}$ & $-2.5^{\circ} /-3.75^{\circ}$ \\
\hline \multirow[t]{2}{*}{ Pacific } & Low & $52.0^{\circ} \mathrm{N} / 172.5^{\circ} \mathrm{W}$ & $-2.5^{\circ} /-3.75^{\circ}$ & $0^{\circ} /-3.75^{\circ}$ & $0^{\circ} /-3.75^{\circ}$ & $-2.5^{\circ} /-7.0^{\circ}$ & $-2.5^{\circ} /-3.75^{\circ}$ \\
\hline & High & $31.7^{\circ} \mathrm{N} / 135.0^{\circ} \mathrm{W}$ & $-2.5^{\circ} /+3.75^{\circ}$ & $0^{\circ} / 0^{\circ}$ & $0^{\circ} /+3.75^{\circ}$ & $0^{\circ} /+3.75^{\circ}$ & $-2.5^{\circ} /+3.75^{\circ}$ \\
\hline
\end{tabular}

Table 5. Annual-mean SLP gradient between subpolar lows and subtropical highs in the Atlantic and Pacific sectors for the control (PI) simulation, and the differences between each sensitivity experiment and the PI simulation. Positive differences indicate a stronger SLP gradient. The SLP gradient has been calculated as the difference between the SLP low and high centers divided by the distance between the centers.

\begin{tabular}{|c|c|c|c|c|c|c|}
\hline & \multirow{2}{*}{$\begin{array}{c}\frac{\nabla \mathrm{SLP}\left(\mathrm{Pa} \mathrm{km}^{-1}\right)}{\mathrm{PI}} \\
\end{array}$} & \multicolumn{5}{|c|}{$\nabla$ SLP difference $\left(\mathrm{Pa} \mathrm{km}^{-1}\right)$} \\
\hline & & LGM & LGMghg & LGMalb & LGMtopo & LGMice \\
\hline Atlantic & 0.50 & +0.21 & +0.06 & +0.18 & 0.0 & +0.19 \\
\hline Pacific & 0.59 & -0.04 & -0.05 & -0.02 & -0.15 & -0.06 \\
\hline
\end{tabular}

broader PI maximum results from a more tilted SW-NE orientation of the Atlantic jet and greater variability in jet position around its climatological mean relative to the LGM simulations (not shown).

The complicated relationship between changes in tropospheric temperature gradients and upper level circulation is beyond the scope of this study, but we do note that whereas topography effects dominate the 200-hpa wind profile in winter, albedo is the major player in summer (Figs. 3 and 4).

LGMtopo has a much lower summer albedo over North America than the full LGM simulation, whereas the albedo in LGMalb is almost the same as in the full LGM simulation throughout the year. Thus, LGMtopo exhibits large surface heating compared to LGMalb and LGM in summer, leading to a weaker meridional temperature gradient between low and mid latitudes at the surface and in the free troposphere (Fig. 4) and, via thermal wind balance, weaker upper level winds.

In winter, the fact that surface albedo changes associated with the ice sheets are not explicitly included in the LGMtopo boundary conditions is not as important because (1) the presence of snow cover increases the albedo in LGMtopo to values similar to those in LGMalb/LGM, and (2) solar insolation is greatly reduced for much of the season. As a result, the winter LGM-PI changes in 200-hPa zonal wind are almost entirely explained by topography changes (LGMtopo, Fig. 3). In fact, the shape of the zonally averaged zonal wind profiles and the positions of the maxima are nearly identical in the LGMtopo experiment and the full LGM simulation during winter (Fig. 3).

In the annual mean, the combined effects of ice sheet albedo and topography in LGMice thus produce most of the strengthening and northward shift of the jet seen in the glacial climate compared to the modern climate.

As seen in Sect. 3.1, SLP mean state and variability changes are most strongly associated with changes in topography. This section has shown that topography is also the leading factor in determining the upper tropospheric zonal wind field (orientation, shape and intensity) during winter, and that both LGM albedo and topography affect the uppertropospheric zonal winds during the summer months.

\subsection{Surface temperature}

In the coupled experiments performed for this study, the SST field is calculated as part of the model's response to the imposed GHG, topography and/or albedo boundary conditions. SST is known to have an important influence on the atmosphere, able to alter features of its mean state, its variability, and the persistence of atmospheric anomalies (e.g. Czaja and Frankignoul, 1999; Watanabe and Kimoto, 2000; Frankignoul and Kestenare, 2005; Rhines et al., 2008). Thus, an examination of the surface temperature response in each of the sensitivity experiments is of interest to our discussion about atmospheric variability. We will show surface temperature 
$\mathrm{PI}$

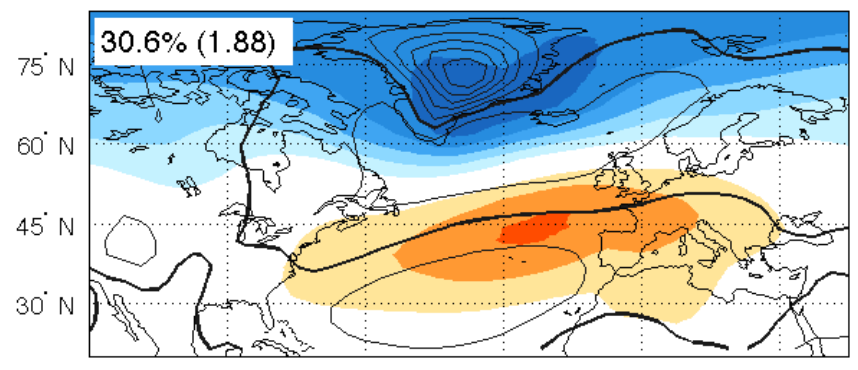

LGMghg

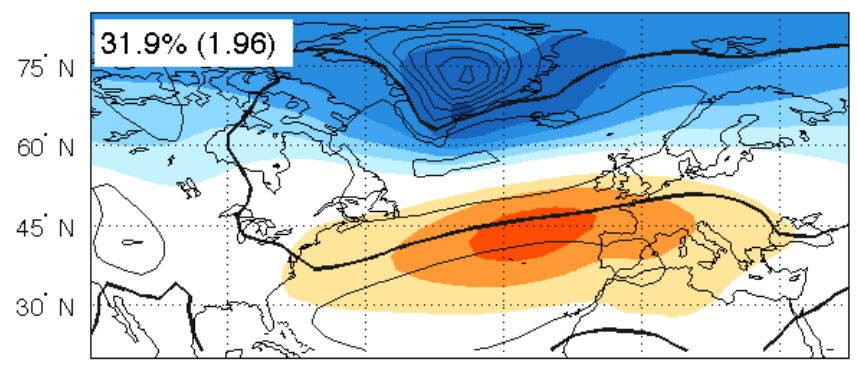

LGMalb

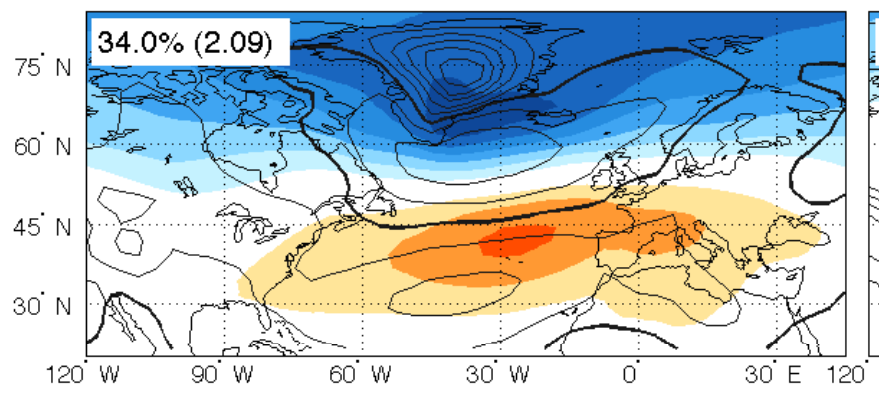

LGM

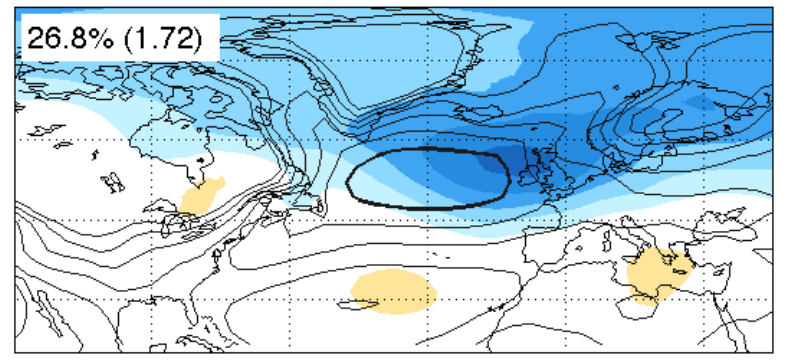

LGMice

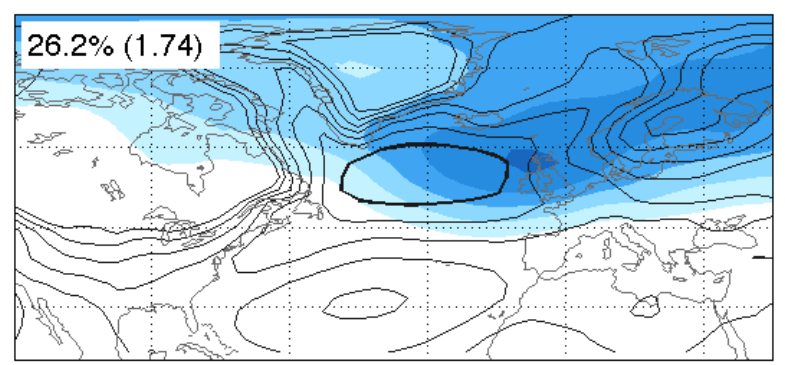

LGMtopo

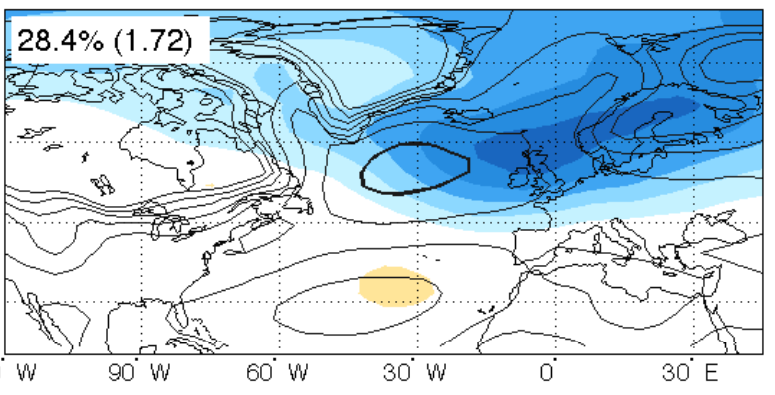

\begin{tabular}{lllllllllllll|ll|l}
\hline-9 & -8 & -7 & -6 & -5 & -4 & -3 & -2 & -1 & 0 & 1 & 2 & 3 & 4
\end{tabular}

Fig. 2. Leading EOF of monthly SLP anomalies (colored shading: $\mathrm{hPa} /$ standard deviation of PC) within the domain shown, using data from all months and SLP climatology (contours: $4 \mathrm{hPa}$ interval from 1000 to $1040 \mathrm{hPa}$; higher values omitted for clarity; bold contour denotes $1016 \mathrm{hPa}$ ) in the North Atlantic sector for the control (PI) and LGM simulations, and for the sensitivity experiments. Numbers show the amount of variance explained by the first EOF both as a percentage of the total variance $\left(\lambda_{1}\right)$ and as a standard deviation $\sigma_{\mathrm{NA}}$ in hPa $\left(\sqrt{\lambda_{1} \sigma_{\mathrm{NA}}^{2}}\right)$.

(TS), which over the ocean is defined to be equal to SST (except over sea ice) in the IPSL model and provides information about large-scale atmospheric features (e.g. subsidence warming at the edges of the ice sheets) that will be revisited in the discussion section.

The full LGM simulation shows generally cooler surface temperature relative to PI (Fig. 5) over the whole Atlantic sector. The cooling is concentrated over the ice sheets mostly due to higher topography (LGMtopo) and changed albedo (LGMalb), and at high latitudes due to a polar amplified temperature response associated with sea ice expansion.

Surprisingly, there is a large and widespread warming as well as a sea ice edge retreat over the North Atlantic in the LGMtopo experiment relative to the PI simulation (Fig. 5).
We note that LGMtopo shows increased Atlantic northward heat transport by the atmosphere and ocean, compared to the PI simulation (Fig. 6). The full LGM simulation also shows increased Atlantic heat transports, but does not exhibit surface warming compared to the PI simulation (Fig. 5), probably because of the cooling effect of lower GHG concentrations and increased albedo at high latitudes.

The simulated increase in the Atlantic northward heat transport in the full LGM simulation may not be supported by proxies (Lynch-Stieglitz et al., 2007) and could therefore be a questionable response of the model to topographic forcing. However, there are few proxies for the strength of the Atlantic Meridional Overturning Circulation and their interpretation is not straightforward since the total transport cannot 

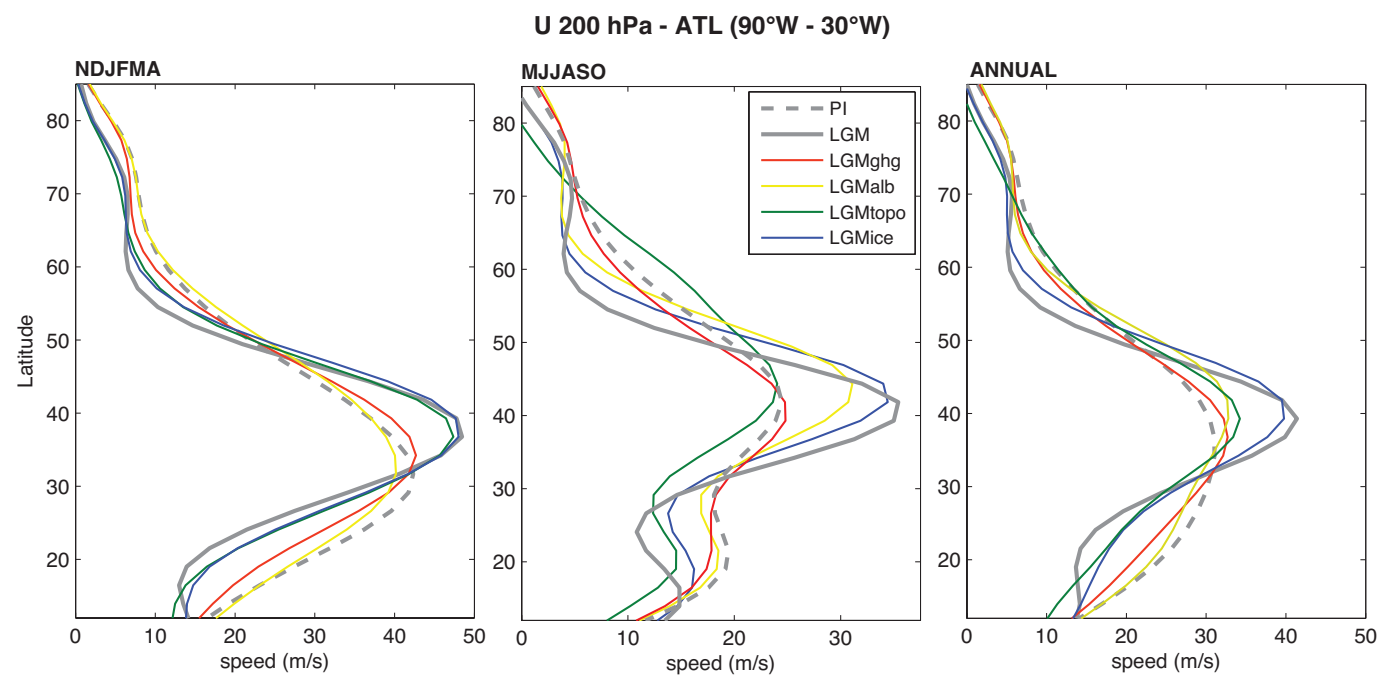

Fig. 3. Climatological-mean zonal wind speed distribution at $200-\mathrm{hPa}$ averaged over the longitudes $\left(90^{\circ} \mathrm{W}-30^{\circ} \mathrm{W}\right)$ in the Atlantic sector for the different experiments in winter (November to April, left), summer (May to October, middle) and for all months (right). The longitudinal domain is chosen to focus on the jet core.
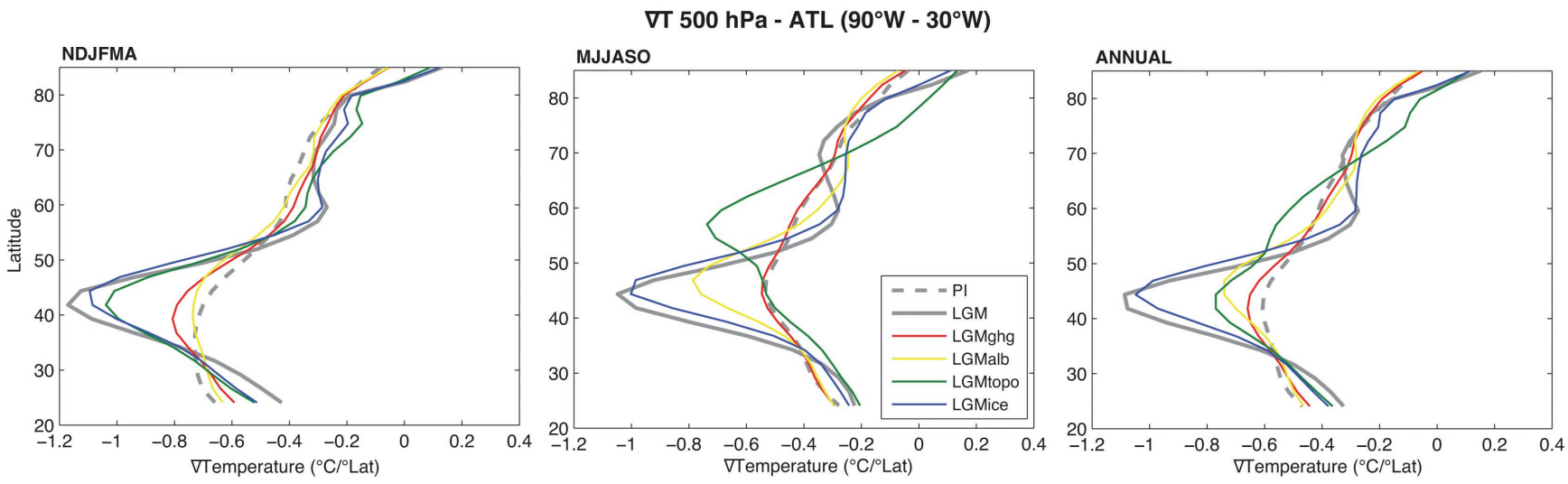

Fig. 4. November to April (left), May to October (middle) and annual (right) $500 \mathrm{hPa}$ zonal temperature gradients $\left(90^{\circ} \mathrm{W}-30^{\circ} \mathrm{W}\right.$ ) as a function of latitude for each experiment. Temperature gradients are calculated over the same longitudinal domain used for the 200-hPa zonal winds in Fig. 3.

be inferred from isolated sections (Wunsch, 2003). In addition, there is no agreement among AOGCMs about the simulated Atlantic Meridional Overturning Circulation during the LGM compared to PI. Some models produce a stronger overturning cell associated with the North Atlantic Deep Water formation that either descends deeper into the water column or is unchanged in vertical extent (Otto-Bliesner et al., 2007; Weber et al., 2007); other models produce a weaker and shallower overturning cell associated with the North Atlantic Deep Water formation (Otto-Bliesner et al., 2007; Weber et al., 2007; Brandefelt and Otto-Bliesner, 2009).

Even though the LGMtopo experiment has a substantially warmer North Atlantic, the large-scale atmospheric circulation features of LGMtopo resemble those of the full LGM simulation, as shown in the previous sections. This result suggests that surface ocean temperatures do not greatly affect the mean atmospheric circulation in the presence of large topographic features such as the Laurentide ice sheet. The additional fresh water experiment (LGMfw) corroborates this result. The LGMfw experiment exhibits widespread cooling over the entire North Atlantic and an expansion of the sea ice edge relative to the full LGM (cf. Figs. 5 and 7a), but the SLP pattern and the leading pattern of SLP variability resemble the full LGM simulation (cf. Figs. 2 and 7b). 


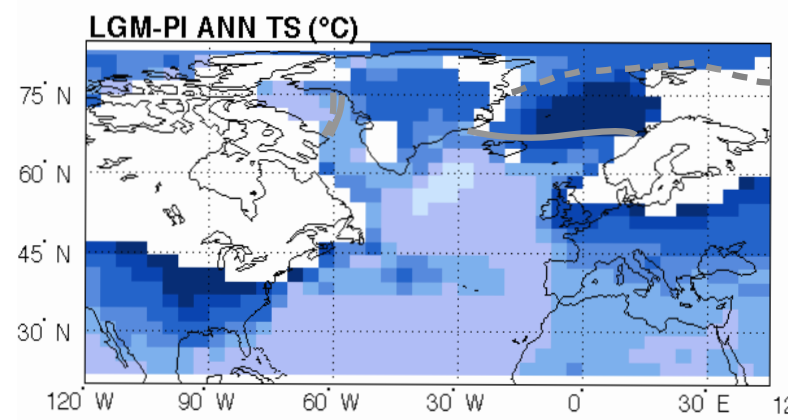

\section{LGM fW-PI ANN TS $\left({ }^{\circ} \mathrm{C}\right.$}
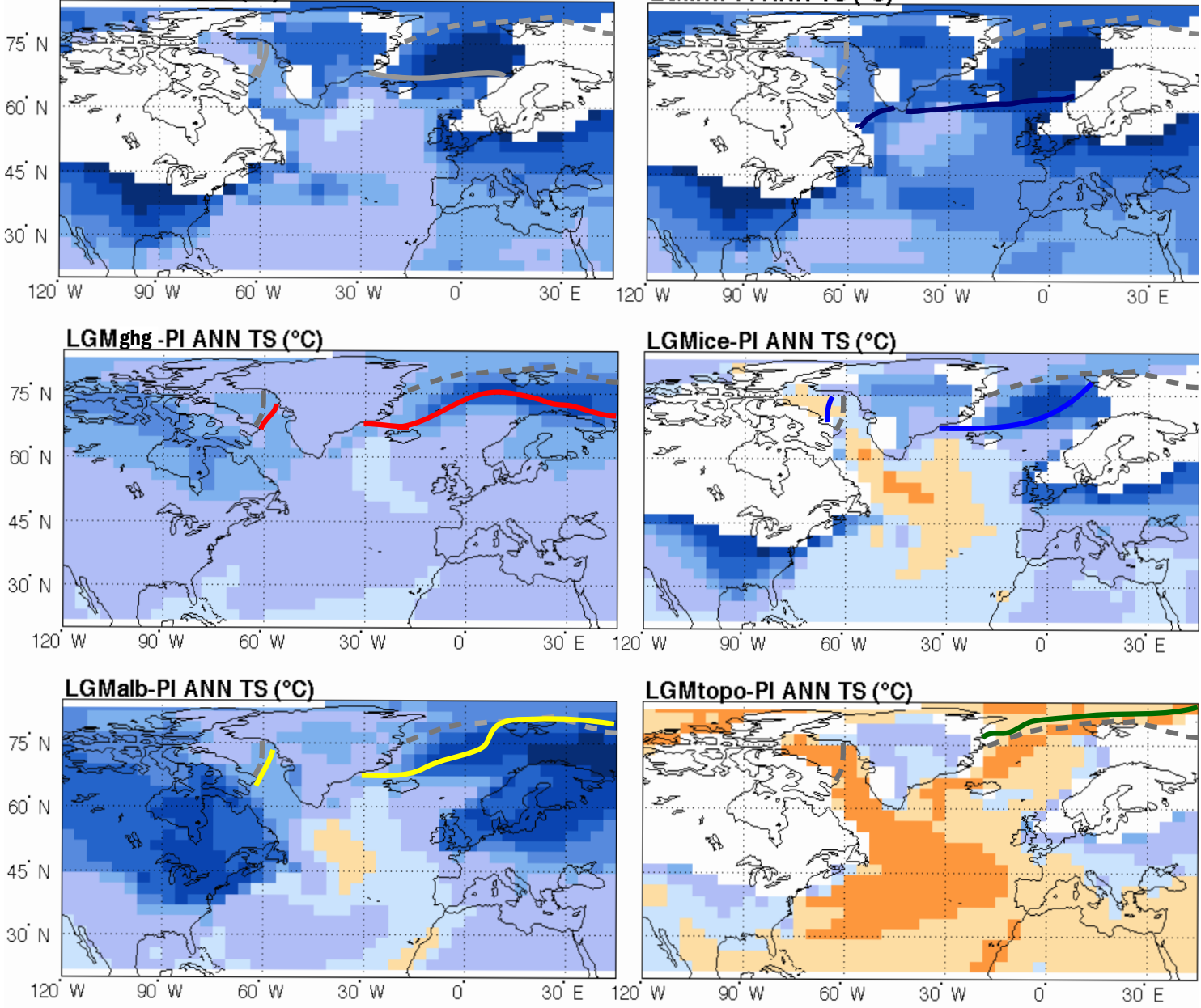

LGMtopo-PI ANN TS $\left({ }^{\circ} \mathrm{C}\right)$
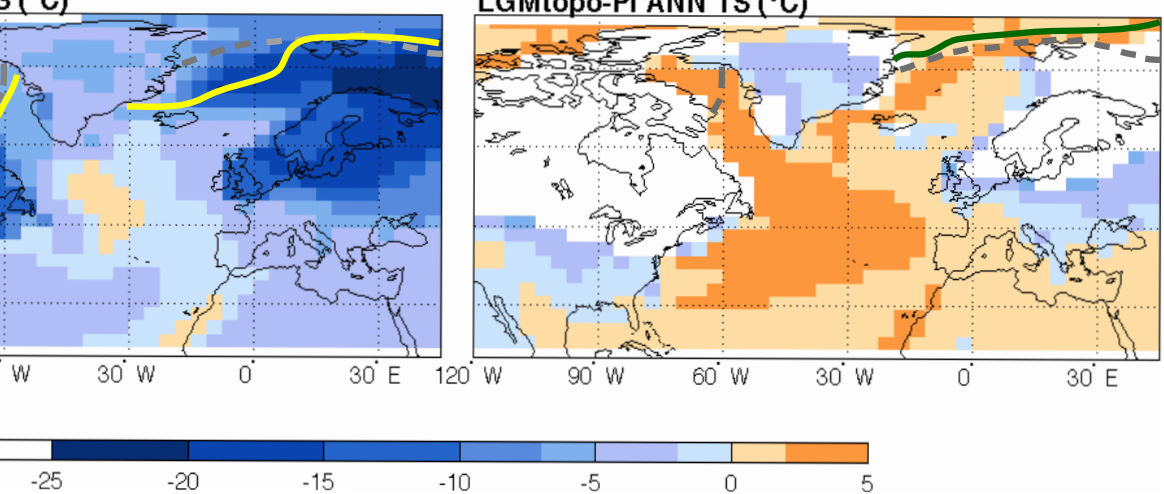

Fig. 5. Anomalies in annual mean surface temperature (TS) relative to the PI climate for each sensitivity experiment. Areas where the topography difference between the experiments and the PI is greater than $500 \mathrm{~m}$ are masked out in white. The annual mean $50 \%$ ice concentration line is indicated by the gray dashed line for the control (PI) experiment and the solid line for each experiment.

\section{Discussion}

We have presented results from sensitivity experiments carried out with a coupled atmosphere-ocean general circulation model showing the impact of various LGM boundary conditions on the mean state and variability of the atmospheric circulation. Each LGM boundary condition has been applied separately to investigate its individual impact relative to a control PI simulation.

Our study shows that ice sheet topography plays a dominant role in altering the mean state and variability of the large-scale atmospheric circulation, particularly in the North Atlantic. This is consistent with previous model studies $(\mathrm{Li}$, 2007; Li and Battisti, 2008; Pausata et al., 2009; Langen and Vinther, 2009), including those (Kageyama et al., 1999;
Justino et al., 2005) that used alternative ice sheet reconstructions such as ICE-4G (Peltier, 1994). Ice sheet topography also influences SSTs, causing a widespread surface warming over the North Atlantic (experiment LGMtopo). Despite this SST warming, features such as the winter 200-hPa zonal wind field, the annual mean SLP distribution and SLP variability are very similar in LGMtopo and the full LGM simulation (Sect. 3.3).

Uncoupled AGCM studies (e.g. Rind, 1987) and studies with AGCMs coupled to a slab ocean (e.g. Manabe and Broccoli, 1985; Felzer et al., 1996, 1998) have already reported a warming in the presence of North American and Fennoscandian ice sheets, particularly in the regions south of the ice sheets and in the northernmost North Atlantic, east of Greenland. They attribute this localized warming to 


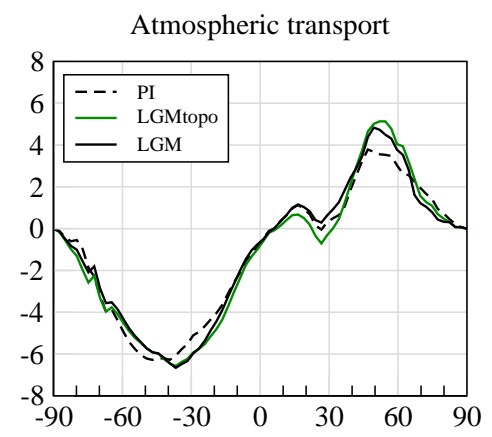

Total Atlantic transport

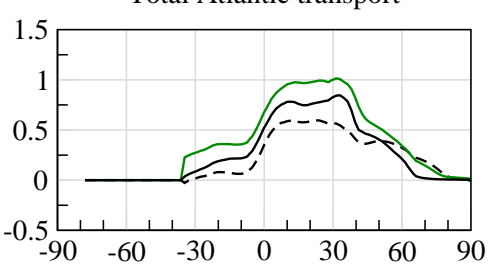

Atlantic transport by overturning

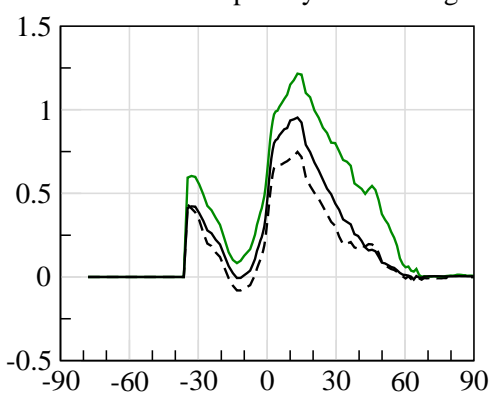

Fig. 6. Northward heat transport (PW, vertical axis) in the atmosphere (upper), in the North Atlantic ocean (middle), and by the North Atlantic overturning circulation (lower) as a function of latitude (horizontal axis).

thermal anticyclones (over the ice sheets), which are associated with subsidence; reduced summer cloud cover; and a generally deeper Icelandic low in winter, which is associated with stronger southwesterly winds and a consequent warming in the northernmost North Atlantic. However, the warming observed in our experiment (LGMtopo) is much broader than the warming observed in these previous uncoupled or partially coupled studies, suggesting that the proposed explanations (subsidence downstream of ice sheets and deepening of the Icelandic low) are insufficient for explaining the response in the fully coupled framework of our experiments. The increased atmosphere and ocean heat transport into the North Atlantic (Fig. 6) likely provides an additional contribution to the warming.

The other boundary conditions, such as GHG concentrations and land ice albedo, have a much smaller and sometimes opposite influence to that of topography, depending on the season and latitude band of interest. The main atmospheric responses to the reduced GHGs are a widespread surface cooling that is more intense at high latitudes (Fig. 5) and a more zonally oriented 200-hPa wind structure in the Atlantic sector relative to the control PI simulation (Fig. 8). There is little change in the strength of the jet itself in LGMghg compared to PI (Fig. 3), consistent with the fact that there is also little change in the midtropospheric temperature gradients (Fig. 4). The importance of mid-tropospheric changes for determining jet strength has also been noted in future scenarios with increased GHG concentrations, where it appears that strengthened mid-to-upper tropospheric gradients are often simulated to win out over weakened surface gradients to increase jet-level wind speeds (as shown for example in Räisänen, 2003).

While this study has corroborated the suggestion of Pausata et al. (2009) that surface ocean changes play a secondary role to topography in determining the large scale atmospheric circulation features at the LGM, unresolved questions remain. In this particular coupled model (IPSL), widespread North Atlantic warming (LGMtopo) or cooling (LGMfw) along with the associated sea ice changes do not greatly affect the climatological SLP field or its leading pattern of variability under LGM boundary conditions. A similar insensitivity of SLP and SLP variability to surface ocean changes was also found in an uncoupled atmosphere model (CAM3, Collins et al., 2006), not only under LGM boundary conditions but also with modern (PI) topography (Pausata et al., 2009, Fig. 6). In contrast, Byrkjedal et al. (2006) found substantial changes in LGM SLP variability associated with SST/sea ice changes, also in an uncoupled set up. Possible reasons for the discrepancy are the use of a different atmosphere model (ARPEGE, Déqué et al., 1994), or the fact that the Byrkjedal et al. (2006) experiments include large sea ice changes quite far south (down to $45^{\circ} \mathrm{N}$ ) in the North Atlantic compared to all the experiments in this study and in Pausata et al. (2009), all of which remain relatively ice-free south of $55^{\circ} \mathrm{N}$ except in the Labrador Sea. Indeed, Kageyama et al. (1999) showed a strong link between the sea-ice edge and the upper level jet-stream in PMIP1 experiments with prescribed or computed (via a slab ocean) SSTs and sea ice as long as the sea ice edge was far enough south, in the midlatitude North Atlantic.

Together with previous studies, the results presented here highlight some major challenges for model intercomparisons of LGM simulations. Pausata et al. (2009) found that SLP and SLP variability were different in LGM simulations performed with different coupled climate models, but seemingly not because of differences in SST/sea ice distributions (Fig. 6 in Pausata et al., 2009). This led to a speculation that simulated large-scale flow characteristics in drastically altered climate states may differ from model to model because of the model-dependent treatment of the topographic boundary condition. The present study has reinforced the primary role of topography over the other boundary conditions in setting the atmospheric circulation (even when coupled ocean 
a)

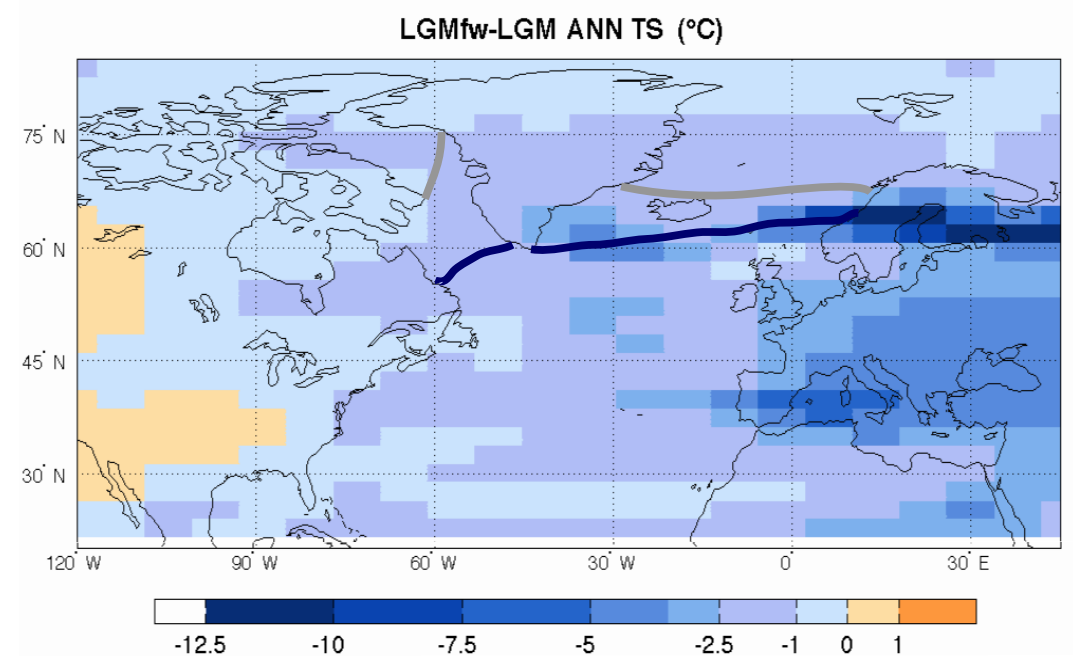

b)

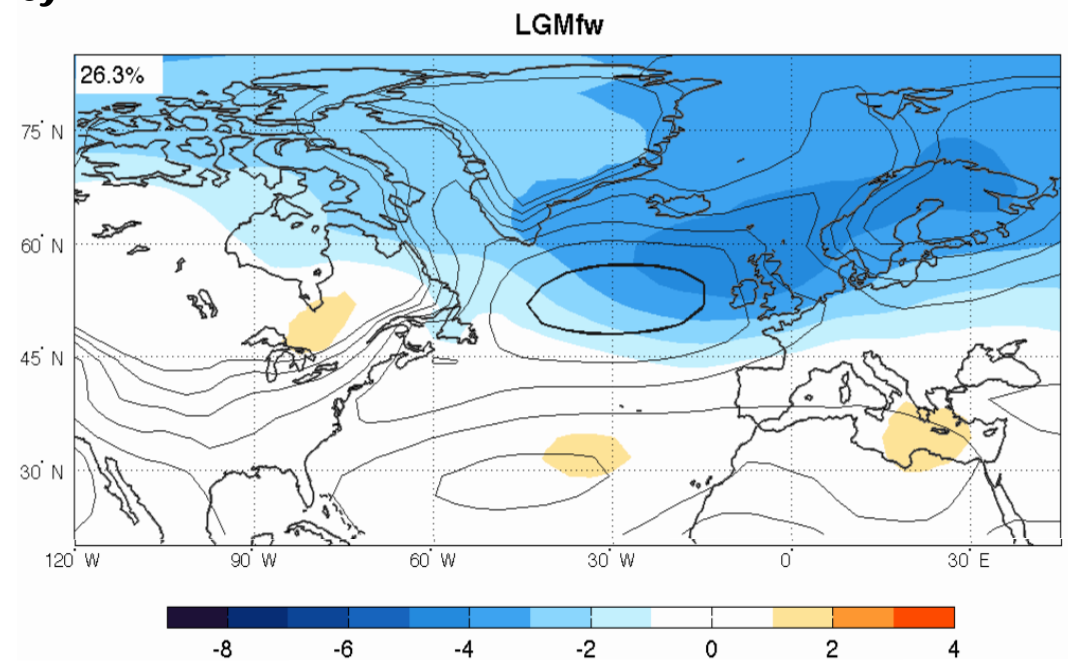

Fig. 7. (a) Changes in the LGMfw annual mean surface temperature (TS) relative to the LGM climate and b) the leading EOF of monthly SLP anomalies (colored shading: $\mathrm{hPa}$ /standard deviation of $\mathrm{PC}$ ) using all months shown along with the SLP climatology (contours: $4 \mathrm{hPa}$ interval from 1000 to $1040 \mathrm{hPa}$; higher values omitted for clarity; bold contour denotes $1016 \mathrm{hPa}$ ) in the North Atlantic sector for the LGMfw simulation. The annual mean $50 \%$ sea ice concentration line is indicated by the gray line for the LGM experiment and by the blue line for the LGMfw experiment. The leading EOF of SLP variability explains $26.3 \%$ of the total variance, as indicated.

feedbacks come into play). It has also reinforced the fact that a direct link between SST/sea ice changes and fundamental features of the atmospheric circulation is not clear in coupled LGM simulations. Given that Pausata et al. (2009) showed a similar lack of a well-defined ocean-atmosphere relationship for uncoupled LGM and PI simulations, it is possible that presumed links between SST and atmospheric circulation in a future, enhanced GHG world may be similarly obfuscated. Systematic studies using suites of coupled and uncoupled models are needed to further clarify the reasons for the model-dependence of the large scale circulation response in simulations of the LGM.

\section{Conclusions}

In this study, we analyze how gross features of the atmospheric general circulation are altered by each Last Glacial Maximum (LGM) boundary condition in a coupled climate model. The main findings are:

- Ice sheet topography sets many features of the SLP field, including the location of the subtropical highs and subpolar lows, the interannual variability, and the leading pattern of variability in the North Atlantic sector. Topography further controls the position, strength and 


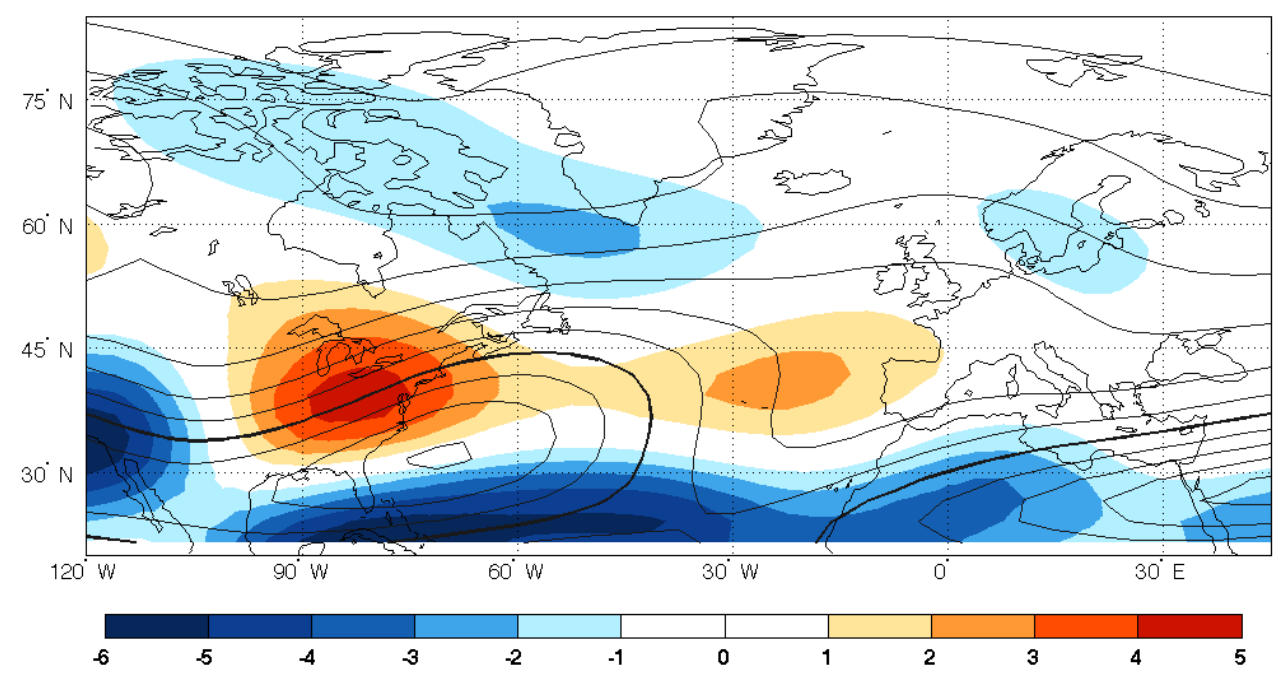

Fig. 8. Winter (November to April) 200-hPa zonal winds for the control (PI) simulation (contours: $5 \mathrm{~m} \mathrm{~s}^{-1}$ interval from 5 to $50 \mathrm{~m} \mathrm{~s}^{-1}$; bold contour at $35 \mathrm{~m} \mathrm{~s}^{-1}$ ) and the difference (shading) between the LGMghg experiment and the control run (LGMghg-PI).

shape of the zonal wind field at $200 \mathrm{hPa}$ in the North Atlantic, especially during winter, while in summer the albedo is also a leading factor.

- Applying LGM GHG and ice sheet albedo boundary conditions to a PI simulation increases the gradient between subpolar low and subtropical high SLP centers, whereas LGM topography is less important to this aspect of atmospheric circulation in the North Atlantic sector.

- SST plays only a secondary role in setting the climatological-mean SLP pattern, 200-hPa zonal winds, the interannual variability of SLP, or the leading pattern of SLP variability in the North Atlantic, supporting the suggestions proposed by Pausata et al. (2009).

Acknowledgements. This work is part of the ARCTREC project and funded by the Norwegian Research Council. The simulations were performed on the NEC-SX8 computer at Centre de Calcul Recherche et Technologie (CCRT), Commissariat à l'Energie Atomique (CEA). This is publication no. A335 from the Bjerknes Centre for Climate Research.

\section{Edited by: H. Renssen}

\section{References}

Braconnot, P., Otto-Bliesner, B., Harrison, S., Joussaume, S., Peterchmitt, J.-Y., Abe-Ouchi, A., Crucifix, M., Driesschaert, E., Fichefet, Th., Hewitt, C. D., Kageyama, M., Kitoh, A., Lan, A., Loutre, M.-F., Marti, O., Merkel, U., Ramstein, G., Valdes, P., Weber, S. L., Yu, Y., and Zhao, Y.: Results of PMIP2 coupled simulations of the Mid-Holocene and Last Glacial Maximum -
Part 1: experiments and large-scale features, Clim. Past, 3, 261277, doi:10.5194/cp-3-261-2007, 2007.

Brandefelt, J. and Otto-Bliesner, B. L.: Equilibration and variability in a Last Glacial maximum climate simulation with CCSM3, Geophys. Res. Lett., 36, L19712, doi:10.1029/2009GL040364, 2009.

Byrkjedal, O., Kvamsto, N., Meland, M., and Jansen, E.: Sensitivity of last glacial maximum climate to sea ice conditions in the Nordic Seas, Clim. Dynam., 26, 473-487, doi:10.1007/s00382005-0096-2, 2006.

Chiang, J. C. H., Biasutti, M., and Battisti, D. S.: Sensitivity of the Atlantic Intertropical Convergence Zone to Last Glacial Maximum boundary conditions, Paleoceanography, 18, 1094, doi:10.1029/2003PA000916, 2003.

Collins, W. D., Rasch, P. J., Boville, B. A., Hack, J. J., McCaa, J. R., Williamson, D. L., Briegleb, B. P., Bitz, C. M., Lin, S. J., and Zhang, M. H.: The formulation and atmospheric simulation of the Community Atmosphere Model version 3 (CAM3), J. Climate, 19, 2144-2161, 2006.

Czaja, A. and Frankignoul, C.: Influence of the North Atlantic SST on the atmospheric circulation, Geophys. Res. Lett., 26, 29692972, 1999.

Dallenbach, A., Blunier, T., Fluckiger, J., Stauffer, B., Chappellaz, J., and Raynaud, D.: Changes in the atmospheric $\mathrm{CH} 4$ gradient between Greenland and Antarctica during the Last Glacial and the transition to the Holocene, Geophys. Res. Lett., 27, 10051008, 2000.

Déqué, M., Dreveton, C., Braun, A., and Cariolle, D.: The ARPEGE/IFS atmosphere model - a contribution to the french community climate modeling., Clim. Dynam., 10, 249-266, 1994.

Felzer, B., Oglesby, R. J., Webb, T., and Hyman, D. E.: Sensitivity of a general circulation model to changes in northern hemisphere ice sheets, J. Geophys. Res.-Atmos., 101, 19077-19092, 1996.

Felzer, B., Webb, T., and Oglesby, R. J.: The impact of ice sheets, $\mathrm{CO}_{2}$, and orbital insolation on late quaternary climates: Sensi- 
tivity experiments with a general circulation model, Quat. Sci. Rev., 17, 507-534, 1998.

Flückiger, J., Dallenbach, A., Blunier, T., Stauffer, B., Stocker, T. F., Raynaud, D., and Barnola, J. M.: Variations in atmospheric $\mathrm{N}_{2} \mathrm{O}$ concentration during abrupt climatic changes, Science, 285, 227-230, 1999.

Frankignoul, C. and Kestenare, E.: Observed Atlantic SST anomaly impact on the NAO: An update, J. Climate, 18, 4089-4094, 2005.

Hansen, J., Lacis, A., Rind, D., Russell, G., Stone, P., Fung, I., Ruedy, R., and Lerner, J.: Climate sensitivity: Analysis of feedback mechanisms, AGU monograph, 130-163, 1984.

Hewitt, C. D. and Mitchell, J. F. B.: Radiative forcing and response of a GCM to ice age boundary conditions: cloud feedback and climate sensitivity, Clim. Dynam., 13, 821-834, 1997.

Justino, F., Timmermann, A., Merkel, U., and Souza, E. P.: Synoptic Reorganization of Atmospheric Flow during the Last Glacial Maximum, J. Climate, 18, 2826-2846, 2005.

Kageyama, M., D’Andrea, F., Ramstein, G., Valdes, P. J., and Vautard, R.: Weather regimes in past climate atmospheric general circulation model simulations, Clim. Dynam., 15, 773-793, 1999.

Kageyama, M., Mignot, J., Swingedouw, D., Marzin, C., Alkama, R., and Marti, O.: Glacial climate sensitivity to different states of the Atlantic Meridional Overturning Circulation: results from the IPSL model, Clim. Past, 5, 551-570, doi:10.5194/cp-5-5512009, 2009.

Kim, S. J.: The effect of atmospheric $\mathrm{CO}_{2}$ and ice sheet topography on LGM climate, Clim. Dynam., 22, 639-651, doi:10.1007/s00382-004-0412-2, 2004.

Laîné, A., Kageyama, M., Salas-Mèlia, D., Voldoire, A., Rivière, G., Ramstein, G., Planton, S., Tyteca, S., and Petershmitt, J. Y.: Northern hemisphere storm tracks during the last glacial maximum in PMIP2 ocean-atmosphere coupled models: energetic study, seasonal cycle, precipitation, Clim. Dynam., 32, 593-614, 2009.

Langen, P. L. and Vinther, B. M.: Response in atmospheric circulation and sources of Greenland precipitation to glacial boundary conditions, Clim. Dynam., 32, 1035-1054, 2009.

Li, C.: A general circulation modelling perspective on abrupt climate change during glacial times, Ph.D. thesis, University of Washington, 2007.

Li, C. and Battisti, D. S.: Reduced Atlantic storminess during Last Glacial Maximum: Evidence from a coupled climate model, J. Climate, 21, 3561-3579, doi:10.1175/2007JCLI2166.1, 2008.

Lynch-Stieglitz, J., Adkins, J. F., Curry, W. B., Dokken, T., Hall, I. R., Herguera, J. C., Hirschi, J. J. M., Ivanova, E. V., Kissel, C., Marchal, O., Marchitto, T. M., McCave, I. N., McManus, J. F., Mulitza, S., Ninnemann, U., Peeters, F., Yu, E.-F., and Zahn, R.: Atlantic meridional overturning circulation during the Last Glacial Maximum, Science, 316, 66-69, doi:10.1126/science.1137127, 2007

Manabe, S. and Broccoli, A. J.: The influence of continental ice sheets on the climate of an ice-age, J. Geophys. Res.-Atmos., 90, 2167-2190, 1985.

Marti, O., Braconnot, P., Dufresne, J. L., Bellier, J., Benshila, R., Bony, S., Brockmann, P., Cadule, P., Caubel, A., Codron, F., De Noblet, N., Denvil, S., Fairhead, L., Fichefet, T., Foujols, M. A., Friedlingstein, P., Goosse, H., Grandpeix, J. Y., Guilyardi, E., Hourdin, F., Idelkadi, A., Kageyama, M., G., K., Levy,
C., Madec, G., Mignot, J., Musat, I., Swingedouw, D., and Talandier, C.: Key features of the IPSL ocean atmosphere model and its sesntivity to atmospheric resolution, Clim. Dynam., 34, 1-26, 2010.

Monnin, E., Indermuhle, A., Dallenbach, A., Fluckiger, J., Stauffer, B., Stocker, T., Raynaud, D., and Barnola, J.: Atmospheric $\mathrm{CO}_{2}$ concentrations over the last glacial termination, Science, 291, 112-114, 2001.

Otto-Bliesner, B. L., Hewitt, C. D., Marchitto, T. M., Brady, E., Abe-Ouchi, A., Crucifix, M., Murakami, S., and Weber, S. L.: Last Glacial Maximum ocean thermohaline circulation: PMIP2 model intercomparisons and data constraints, Geophys. Res. Lett., 34, L12706, doi:10.1029/2007GL029475, 2007.

Pausata, F. S. R., Li, C., Wettstein, J. J., Nisancioglu, K. H., and Battisti, D. S.: Changes in atmospheric variability in a glacial climate and the impacts on proxy data: a model intercomparison, Clim. Past, 5, 489-502, doi:10.5194/cp-5-489-2009, 2009.

Peltier, W. R.: Ice Age Paleotopography, Science, 265, 195-201, 1994.

Peltier, W. R.: Global glacial isostasy and the surface of the ice-age Earth: The ICE-5G (VM2) model and GRACE, Annu. Rev. Earth Planet. Sci., 32, 111-149, doi:10.1146/annurev.earth.32.082503.144359, 2004.

Räisänen, J.: $\mathrm{CO}_{2}$-induced changes in atmospheric angular momentum in CMIP2 experiments, J. Climate, 16, 132-143, 2003.

Rhines, P., Häkkinen, S., and Josey, S. A.: Is oceanic heat transport significant in the climate system?, Springer, ch. 4, 2008.

Rind, D.: Components of the ice-age circulation, J. Geophys. Res.Atmos., 92, 4241-4281, 1987.

Rivière, G., Laîné, A., Salas-Mèlia, D., and Kageyama, M.: Link between Rossby Wave Breaking and the North Atlantic Oscillation-Arctic Oscillation in Present-Day and Last Glacial Maximum Climate Simulations, J. Climate, 23, 2987-3008, 2010.

Roche, D. M., Dokken, T. M., Goosse, H., Renssen, H., and Weber, S. L.: Climate of the Last Glacial Maximum: sensitivity studies and model-data comparison with the LOVECLIM coupled model, Clim. Past, 3, 205-224, doi:10.5194/cp-3-205-2007, 2007.

Walker, G. T. and Bliss, E. W.: World Weather, V. Mem. R. Meteorol. Soc., 4, 53-83, 1932.

Watanabe, M. and Kimoto, M.: Atmosphere-ocean thermal coupling in the North Atlantic: A positive feedback, Q. J. R. Meteorol. Soc., 126, 3343-3369, 2000.

Weber, S. L., Drijfhout, S. S., Abe-Ouchi, A., Crucifix, M., Eby, M., Ganopolski, A., Murakami, S., Otto-Bliesner, B., and Peltier, W. R.: The modern and glacial overturning circulation in the Atlantic ocean in PMIP coupled model simulations, Clim. Past, 3 , 51-64, doi:10.5194/cp-3-51-2007, 2007.

Wunsch, C.: Determining paleoceanographic circulations, with emphasis on the Last Glacial Maximum, Quat. Sci. Rev., 22, 371385, 2003.

Yokoyama, Y., Lambeck, K., De Deckker, P., Johnston, P., and Fifield, L. K.: Timing of the Last Glacial Maximum from observed sea-level minima, Nature, 406, 713-716, 2000. 